\title{
Kajian Psikologis Humanistik Abraham Maslow Pada Tokoh Utama Dalam Novel Surat Dahlan Karya Khrisna Pabichara
}

\author{
Nur Amalia ${ }^{1 *}$ \\ Sinta Yulianingsih ${ }^{1}$ \\ ${ }^{1}$ Universitas Muhammadiyah Prof. \\ DR. HAMKA, Jakarta Timur, DKI \\ Jakarta, Indonesia \\ *email: nur21amalia@gmail.com
}

Received: 10 Maret 2020

Accepted: 24 Maret 2020

Published: 25 Maret 2020

doi:

http://dx.doi.org/10.29405/imj.v2i2 .73

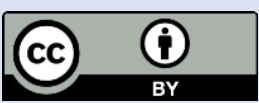

(C) 2020 Oleh authors. Lisensi Imajeri: Jurnal Pendidikan Bahasa dan Sastra Indonesia, Uhamka, Jakarta. Artikel ini bersifat open access yang didistribusikan di bawah syarat dan ketentuan Creative Commons Attribution (CC-BY) license. (http://creativecommons.org/licens es/by/4.0/).

\begin{abstract}
Abstrak
Penelitian yang berjudul Kajian Psikologi Humanistik Abraham Maslow pada Tokoh Utama dalam Novel Surat Dahlan Karya Khrisna Pabicara bertujuan untuk mendeskripsikan aspek psikologis humanistik serta memberikan interpretasi mengenai psikologi humanistik dengan pendekatan psikologi sastra, yang dapat dijadikan sebagai alternatif pembelajaran sastra. Sumber data penelitian ini adalah novel Surat Dahlan yang diterbitkan oleh PT Mizan Publika. Fokus penelitian berupa kajian psikologi humanistik, pada hierarki kebutuhan yaitu, the physiological needs (kebutuhan fisiologis), the safety needs (kebutuhan rasa aman), the belongingness and love needs (kebutuhan cinta dan rasa memiliki-dimiliki), the esteem needs (kebutuhan harga diri), the needs for self-actualization (kebutuhan aktualisasi diri). Metode penelitian yang digunakan adalah desktriptif-kualitatif Hasil penelitian ini menunjukan bahwa, the physiological needs, tokoh utama (Dahlan) berupa pemenuhan makan dan tidur, tercapainya kebutuhan fisiologis Dahlan, ketika ia menemukan makanan yang telah disiapkan untuknya. The safety needs dibutuhkan Dahlan, dalam bentuk perlindungan dan kebebasan dari kejaran tentara. Terpenuhinya kebutuhan rasa aman Dahlan ketika ia terbebas dari kejaran tentara. The belongingness and love needs, dibutuhkan Dahlan dalam bentuk cinta dan kasih sayang dari lawan jenis, yaitu Nafsiah. Kebutuhan ini terpenuhi, ketika Dahlan berhasil menikahi Nafsiah. The esteem needs, yang pertama kali Dahlan dapatkan adalah pujian, pengakuan dan kepercayaan. Seiring melesatnya karir Dahlan, ia mendapatkan lebih banyak kebutuhan harga diri. The needs for selfactualization adalah kebutuhan terakhir, yang berhasil Dahlan penuhi, dibuktikan dengan Dahlan memiliki sifat jujur, pantang menyerah, menghargai orang lain dan menyukai tantangan.
\end{abstract}

Kata kunci: Novel; Psikologi Sastra; Psikologi Humanistik; Pembelajaran Sastra Indonesia

\section{Abstract}

The objective of this research is to know the humanistic psychology of novel Surat Dahlan by Khrisna Pabichara and to give the interpretation of humanistic psychology with a literary approach, that can be used as an alternative in literature learning. The source of this research data is novel Surat Dahlan by Khrisna Pabichara, published by PT Mizan Publika. The research focus is in the form of humanistic psychology studies, the hierarchy of needs is, the physiological needs, the safety needs, the belongingness and love needs, the esteem needs, the needs for self-actualization. Research method used is descriptive-qualitative with the analysis techniques. The results of the research show that, the physiological needs, the main character (Dahlan) is feeding and sleeping. The achievement of Dahlan's physiological needs, when he found food prepared for him. The safety needs, Dahlan needed, a security in the form of protection and freedom. Fulfillment of Dahlan's need for security when he was released from the army. The belongingness and love needs, Dahlan needed in the love from the opposite sex, is Nafsiah. Fulfillment of this need, when Dahlan managed to marry Nafsiah. The esteem needs, the first time Dahlan got was praise, recognition and trust. As Dahlan's career sped up, he gained more esteem. The needs for self-actualization, is the last need, which Dahlan managed to fulfill, by proving that Dahlan had an honest nature, never gave up, respected others and liked challenges.

Keywords: Novel; Literature Psychology; Humanistic Psychology; Indonesian literature learning 


\section{PENDAHULUAN}

Novel yang dikenal di Indonesia berasal dari pelafalan bahasa Inggris yaitu novel. Novel merupakan salah satu karya fiksi yang dihasilkan pengarang, dengan memuat cerita tentang kehidupan tokohnya yang beraneka ragam dan perwatakan secara mendalam. Kehidupan tokoh tak dapat dilepaskan dengan sejumlah pemenuhan kebutuhan demi kelangsungan hidup sang tokoh itu sendiri. Dalam proses pemenuhan kebutuhan itu biasanya selalu diwarnai dengan tingkah laku para tokoh yang nantinya akan mengarah pada kecenderungan dalam mencapai tujuan kehidupan yang diinginkan setiap manusia. Tingkah laku dalam hal ini berkaitan dengan psikologis, berupa cerminan kepribadian dan dapat dilihat dengan kasat mata saat seseorang berusaha memenuhi kebutuhan hidupnya. Dalam memproyeksikan realitas kehidupan yang dituangkan ke dalam teks.

Pada dasarnya Sebuah novel dibangun atas dua unsur yang sangat penting dan diperlukan penulis dalam membangun ruh cerita secara rinci sehingga cerita yang ditulis seolah hidup dan berada di dunia nyata. Unsur yang dimaksud adalah unsur intrinsik dan unsur ekstrinsik. Hal ini sejalan dengan pendapat Nurgiyantoro (2013:29), Priyatni, (2010: 109), Sehandi, (2014: 54) yang mengelompokkan unsur-unsur pembangun novel menjadi dua bagian yakni unsur intrinsik dan ekstrinsik yang secara langsung turut serta dalam membangun cerita. Unsur intrinsik adalah unsur yang melekat pada novel, meliputi tema, latar (setting), sudut pandang (point of view), alur, penokohan, gaya bahasa, dan amanat, sedangkan unsur ekstrinsik ialah unsur yang mempengaruhi penciptaan karya sastra dari luar.

Unsur ekstrinsik dipandang kurang penting, karena agak sulit untuk menemukan unsur ini di dalam sebuah novel. Unsur in dapat ditemukan setelah pembaca memahami unsur intrinsik yang terdapat dalam sebuah novel. karena unsur ini saling berkelindan. Mengetahui dan memahami unsur ekstrinsik adalah penting, mengingat bahwa sebuah karya sastra tidak muncul hanya dari kekosongan budaya. Secara umum unsur ekstrinsik di dalam novel dapat memuat aspek historis, sosiologis, filsafat, religius, dan psikologis.

Psikologi sebagai unsur ekstrinsik dari sebuah novel tentu saja berkaitan dengan psikologi sastra yang mengkaji sebuah karya sastra melalui ilmu psikologi. Lebih tegas lagi Psikologi dan sastra memiliki hubungan fungsional karena sama-sama mempelajari keadaan kejiwaan seseorang secara ilmiah; dalam ilmu psikologi gejala kejiwaan seseorang bersifat rill, sedangkan dalam sastra bersifat imajinatif, sementara kepribadian digambarkan melalui tokoh, Suaka (2014: 229). Dengan demikian dapat ditarik benang merah bahwa psikologi sastra merupakan kajian yang memandang karya sebagai aktivitas kejiwaan. Psikologi sastra identik dengan psikoanalisis, yang muncul dari teori Sigmun Freud yang kemudian dikembangkan dan digunakan dalam kajian psikologi sastra, seperti psikologi humanistik mengenai kepribadian dan tingkah laku manusia yang ditentukan oleh motivasi meraih sesuatu (Maslow, 1954; Minderop, 2013). Tingkah laku manusia lebih ditentukan oleh motivasi untuk mencapai tujuan agar kehidupan si individu lebih berbahagia dan sekaligus memuaskan. Hal ini dapat dilihat dalam Hierarchy of Needs (hierarki kebutuhan) yang berasal dari fakta yang diketahui seseorang kemudian, beranjak pada pengalaman klinis, melakukan observasi serta eksperimental. At the same time conform to the known facts, clinical and observational as well as experimental. It derives most directly, however, from clinical experience, (Maslow, 1954). Ada lima tingkatan yang perlu dicapai setiap individu bila ingin meraih keinginannya namun, apabila ada salah satu dari tingkatan tersebut tidak tercapai maka, mustahil bagi individu tersebut untuk mencapai tingkatan selanjutnya, Maslow (dalam Jarvis: 2010), membedakan D-needs atau Deficiency needs yang muncul dari kebutuhan akan pangan, tidur, rasa aman dan lain-lain, serta B-needs atau being needs seperti keinginan untuk memenuhi potensi diri. 
Hierarki kebutuhan ini dimulai dari kebutuhan yang paling mendasar yang dinamakan dengan D-needs atau deficiency needs oleh Freud dalam Maslow (1954), Mindrop (2013), Jarvis (2012), yaitu (1) The physiological needs (kebutuhan fisiologis) (2) The safety needs (kebutuhan rasa aman) (3) The belongingness and love needs (kebutuhan cinta dan rasa memiliki-dimiliki) (4) The esteem needs (kebutuhan harga diri) dan diakhiri dengan B-needs atau being needs, yang berarti keinginan untuk memenuhi potensi diri (5) The need for selfactualization (kebutuhan aktualisasi diri).

Teori motivasi manusia yang dikembangkan Maslow (1954), Minderop (2013) menyatakan, motivasi adalah bekerja berdasarkan kebutuhan manusia dan mengurutkannya berdasarkan tingkat prioritas manusia dalam pemenuhan kebutuhannya, dorongan atau keinginan yang timbul dari dalam diri setiap individu. Teori ini dapat digunakan dalam mengkaji sebuah karya sastra, terutama pada penggambaran karakter tokoh yang bersifat dinamis sesuai dengan alur cerita.

Novel Sepatu Dahlan mengisahkan tentang perjuangan seorang Dahlan yang berasal dari keluarga yang sangat miskin yang ingin sekali membeli sepatu. Keinginannya itu terlahir sejak dia masih kecil. Kemiskinan bagi penduduk Kebon Dalem bukan halangan untuk menuntut ilmu setinggi mungkin, walaupun harus bekerja nguli panggul, menggarap tanah bengkok, buruh harian di perkebunan tebu, kuli nyeset demi sesuap nasi tiwul dan upah yang hanya diterima sekali setiap bulan.

Dahlan yang dimarahi oleh bapaknya karena lulus mendapat dua nilai merah di dalam ijazahnya, dengan rasa sedih dan peyesalan di dalam hatinya, meskipun begitu Dahlan punya keinginan meneruskan sekoloahnya ke SMP Magetan, sekolah idamannya.

Bapak melarangnya karena faktor biaya dan jauh. Namun Dahlan tidak kekurangan akal agar dapat bersekolah di SMP Magetan. Malam harinya Ia berpura-pura bermimpi bertemu denga Kiyai Mursjid yang sangat dihormati bapaknya. Dahlan mengatakan ia ingin sekolah di SMP Magetan, tetapi Bapaknya tidak kekurangan akal, pagi harinya bapaknya bercerita tentang eorang pemuda yang menggandeng ibunya yang sudah uzur dari negeri Yaman ke tanah suci untuk berangkat haji. Setelah mendengar cerita dari bapaknya Dahlanpun memutuskan untuk bersekolah di Pesantren Takeran, karena keluarganya semuanya bersekolah di sana. Dahlanpun masuk ke Pesantren Takeran dengan melewati masa orientasi yang menyenangkan terutama dengan kata-kata sambutan yang bijak dari Ustadz Ikham yang membuat Dahlan bersalah karena selama ini selalu memandang remeh pesantren.

\section{METODE}

Penelitian ini menggunakan metode penelitian kualitatif. Metode penelitian kualitatif didefinisikan sebagai metode penelitian Ilmu-ilmu Sosial yang mengumpulkan dan menganalisis data berupa kata-kata (lisan maupun tulisan) dan perbuatan-perbuatan manusia serta peneliti tidak berusaha menghitung atau mengkuantifikasikan data kualitatif yang diperoleh dan dengan demikian tidak menganalisis angka-angka (Afrizal, 2016). Penelitian ini berusaha mendeskripsikan data-data yang telah didapatkan dari berbagai referensi bacaan berupa kutipan kata atau kalimat. Penelitian ini menggunakan metode penelitian kualitatif karena data yang digunakan berupa kutipan kata atau kalimat dari tulisan berbentuk cerita pada novel Surat Dahlan karya Khrisna Pabichara, yang kemudian dianalisis sesuai dengan konteks penelitian secara deskriptif.

Sumber data dalam penelitian ini adalah novel Surat Dahlan karya Khrisna Pabichara cetakan pertama tahun 2013, terbitan PT Mizan Publika yang berjumlah 377 halaman, terdiri dari 31 bab. 
Teknik pengumpulan data yang digunakan berupa dokumen dalam bentuk novel. Dokumen merupakan catatan peristiwa yang sudah berlalu. Dokumen dapat berbentuk tulisan, gambar, atau karya-karya monumental dari seseorang. Dokumen yang berbentuk tulisan misalnya catatan harian, sejarah kehidupan (life histories), ceritera, biografi, peraturan kebijakan, Sugiyono (2014). Dokumen yang digunakan dalam penelitian ini berupa tulisan dalam bentuk cerita, yaitu novel Surat Dahlan karya Khrisna Pabichara, dengan prosedur pengumpulan data sebagai berikut:

a. Peneliti membaca novel Surat Dahlan karya Khrisna Pabichara berulang-ulang sampai paham betul dengan isi novel ini.

b. Membaca buku referensi yang berhubungan dengan penelitian.

c. Membuat tabel analisis.

d. Menentukan hierarki kebutuhan (tingkatan kebutuhan) berdasarkan kepribadian atau psikologi tokoh utama sesuai dengan teori Abraham Maslow.

e. Mengelompokan data berdasarkan kriteria analisis.

f. Memasukan data ke dalam tabel analisis.

Teknik analisis data pada penelitian ini menggunakan model Miles and Huberman. Aktivitas dalam analisis data kualitatif dilakukan secara interaktif dan berlangsung secara terus menerus sampai tuntas, sehingga datanya sudah jenuh. Aktivitas dalam analisis data, yaitu data reduction, data display, dan conclusion drawing/verification, Miles and Huberman (dalam Sugiyono, 2014).

Pemeriksaan keabsahan data dalam penelitian ini menggunakan triangulasi data. Triangulasi dalam pengujian kredibilitas ini diartikan sebagai pengecekan data dari berbagai sumber dengan berbagai cara, dan berbagai waktu (Sugiyono, 2016). Pemeriksanaan keabsahan data ini dapat dilihat dari:

a. Penulis dan pengamat ahli, berupa ketentuan penelitian, pendapat, masukan pengamat ahli mengenai penelitian yang dilakukan.

b. Hasil analisis dan interpretasi data.

c. Barbagai sumber bacaan dan rujukan yang dapat dipertanggungjawabkan.

\section{HASIL DAN PEMBAHASAN}

Novel Surat Dahlan karya Khrisna Pabichara sebagai objek dalam penelitian ini akan dianalisis berdasarkan lima tingkatan atau hierarki kebutuhan yang terdiri dari the physiological needs (kebutuhan fisiologis), the safety needs (kebutuhan rasa aman), the belongingness and love needs (kebutuhan cinta dan rasa memiliki-dimiliki), the esteem needs (kebutuhan harga diri), dan the need for self-actualization (kebutuhan aktualisasi diri).

\section{The Physiological Needs (Kebutuhan Fisiologis)}

The physiological needs (kebutuhan fisiologis), merupakan kebutuhan untuk mempertahankan hidup individu secara fisik. Pada novel Surat Dahlan, kebutuhan fisiologis yang dibutuhkan oleh tokoh utama (Dahlan) berupa tidur dan makan. Hal ini terdapat pada kutipan berikut :

"Setelah minum obat, saat perawat meninggalkan kamar, aku ingin tidur. Aku sangat mengantuk. Namun, mataku tetap terpincing. "Tidurlah, Mas," kata Nafsiah sambil mengelus pipiku. "Aku lagi cemas....." "Tidak ada yang perlu dicemaskan!" "Bagaimana kalau liver ini berasal dari seorang pemuda yang urakan?" "Dulu Mas Dahlan juga urakan!” tandas Nafsiah sambil terkekeh,” (Pabichara: hlm. 11).

"Ketika terbangun, hari sudah pagi. Cahaya matahari menerobos lewat sela-sela papan. Dengan sedikit memutar leher, aku lihat pintu rumah tertutup rapat. Aku coba 
menggerakkan jari-jari tangan, berhasil. Mengangkat tungkai kaki, berhasil. Sewaktu aku berusaha bangkit, rasa nyeri menjalar di punggung. Tidak ada siapa-siapa. Senyap. Saripa, nenek yang mulutnya penuh sirih, mungkin sedang keluar. Kepalaku pusing karena lelah dan kelaparan. Aku berharap dikaruniai cukup tenaga agar dapat bertahan hidup. Merasa sedih dan amat merana, aku mencoba berdiri. Namun, lututku goyah," (Pabichara: hlm. 145).

\section{The Safety Needs (Kebutuhan Rasa Aman)}

Kebutuhan the safety needs (kebutuhan rasa aman) merupakan kebutuhan yang berkaitan dengan kekhawatiran, kebebasan, rasa takut, membutuhkan perlindungan dan lainnya yang membuat individu merasa terancam. Kebutuhan rasa aman Dahlan terlihat pada kegagalan Dahlan dalam memimpin aksi unjuk rasa bersama teman-temannya, yang membuat Dahlan menjadi cemas dan takut. Ketakutan Dahlan semakin menjadi ketika dua orang tentara menghampirinya dan menodongkan senjatanya tepat menyentuh dahi Dahlan. Berikut kutipan yang menceritakan ketakutan Dahlan.

"Dua orang tentara mendekat, semakin dekat. Sepatu lars itu menerbangkan debu setiap menepak di jalan. "Siapa yang pimpin aksi ini!?" cecar tentara yang berbadan lebih tinggi. Aku tercekat. Yang lain terdiam. "Aku!" Lengan tentara itu terayun di udara, pucuk senapan kurang seberapa senti saja dari dahiku. Pikiranku mengembara kemana-mana, ngeri membayangkan nyawaku dihabisi dengan satu peluru menembus dahi, cemas membayangkan perasaan Mbak Atun jika mendengar kabar aku meninggal pada saat unjuk rasa, atau Bapak yang tergugu karena tak akan pernah melihatku lagi, lalu ciut nyaliku melihat pucuk senapan teracung. Ujungnya yang dingin menyentuh dahiku, menggigilkan tulang-tulangku," (Pabichara: hlm. 120121).

Rasa cemas dan takut Dahlan membuktikan, ia membutuhkan the safety needs (kebutuhan rasa aman) dalam hal perlindungan, dan kebebasan.

"Butuh beberapa saat bagiku untuk mencerna apa yang sedang terjadi. Letusan bedil dari salah satu tentara memulihkan kesadaranku lebih cepat. Satu-satunya yang ingin kulakukan saat ini adalah sesegera mungkin berlari. Aku berlari membabi buta. Berlari sejauh-jauhnya, sampai letupan dan bentakkan tak lagi terdengar. Berbelok ke gang, menyelinap di sela-sela rumah-rumah kayu. Berbelok menghindari jalan raya. Terus berlari. Tak ada rasa letih. Yang ada cuma rasa takut. Keringat dan napas ngos-ngosan tak kupedulikan," (Pabichara: hlm. 121-122).

\section{The Belongingness and Love Needs (Kebutuhan Cinta dan Rasa Memiliki-dimiliki)}

Setiap individu akan berusaha mencapai atau memenuhi kebutuhan ini hingga individu tersebut benar-benar mendapatkan cinta dan kasih seperti yang diinginkannya. Dalam hal ini, Dahlan merasa bahwa dirinya telah jatuh cinta dan ia ingin sekali memastikannya.

"Sesungguhnya bukan Kampung Mancong atau Sungai Ahong yang ingin kulihat. Ada seseorang di sana, di Tanjung Isuy, yang belakangan ini begitu kuat membetot ingatan dan anganku. Semula kukira aku telah jatuh cinta. Namun, aku tidak terlalu yakin," (Pabichara: hlm. 253).

Kutipan di atas menjelaskan awal mula Dahlan jatuh cinta kepada Nafsiah. Dahlan membutuhkan cinta dan kasih dari seseorang yang ia harapkan. Keinginan Dahlan dalam 
memenuhi kebutuhan ini terlihat ketika Dahlan bertekad untuk menemui Nafsiah yang sedang berada di rumah neneknya. Hal ini terdapat pada kutipan berikut, yang merupakan bentuk dari usaha individu dalam memenuhi the belongingness and love needs (kebutuhan cinta dan rasa memiliki-dimiliki).

"Maka, lajulah sepeda, lajulah! Jalan berbatu dan berlubang tak kuindahkan. Aku harus segera tiba di Karang Mumus, di rumah neneknya Nafsiah. Cukup sudah kegagalan di Tanjung Isuy. Aku tidak mau jatuh ke lubang yang sama. Peluang, terkait dengan urusan hati, harus kuraih dengan gesit," (Pabichara: hlm. 268).

“Terus terang, aku gugup. Semula aku membayangkan ayah Nafsiah akan marah besar, mengamuk-amuk, dan menghina-hina kedatanganku. Bayangkan saja, aku datang melamar anak gadisnya menjelang tengah malam. Aku pikir dia akan menceramahiku dengan petuah-petuah membosankan tentang "stabilitas nasional", "aman terkendali", "dwifungsi ABRI", "hankamrata", atau "ipoleksosbudhankam," (Pabichara: hlm. 281).

\title{
The Esteem Needs (Kebutuhan Harga Diri)
}

Kebutuhan harga diri merupakan kebutuhan yang merujuk pada sebuah penghargaan, percaya diri, nama baik, jabatan, pengakuan dan lainnya, yang berasal dari diri sendiri ataupun orang lain.

\begin{abstract}
"Sekarang, giliranku tersenyum. Tentu saja sambil meraih amplop cokelat berisi gaji bulan pertamaku. "Terima kasih,Bbang." "Kau hebat, Ding." Setahuku, dia jarang memuji. Dia lebih banyak menguji. Barangkali dia sedang menguji aku dengan cara yang tak lazim. Aku belum bisa melupakan bagaimana alisnya tatkala sedang bertaut, suaranya melengking tinggi, dan gebrakannya di meja yang nyaris memaksa jantungku meninggalkan tempatnya. Aku ingat semua itu, tapi aku tak sakit hati. Aku anggap itu sebagai metode yang dia pilih untuk mematangkan jiwaku. Dengan begitu, aku terus terlecut. "Apa yang akan kau tulis pekan depan?" tanyanya. Dengan malu-malu, aku menjawab, "Belum tahu, Bang." BAku sepakat dengan pendapat bang Sayid," ujarnya, berhenti sejenak, "Kau memang punya potensi. Aku suka caramu menyajikan berita. Sesuatu yang sederhana bisa bernyawa di tanganmu. Kata-kata yang kau pilih juga mudah dicerna, tanpa harus kehilangan kedalaman. Tapi...." (Pabichara: hlm. 221).
\end{abstract}

Pada kutipan di atas, Dahlan menerima pengakuan dan pujian atas potensi yang dimilikinya. Bentuk dari kebutuhan harga diri yang berasal dari orang lain yang paling sederhana adalah pengakuan, pujian dan kepercayaan. Hal ini membuktikan bahwa Dahlan telah mendapatkan kebutuhan harga diri dalam bentuk pengakuan dan pujian yang berasal dari orang lain, atas kerja keras yang dilakukannya tanpa mengeluh walau sering kali dimarahi.

\section{The Need For Self-Actualization (Kebutuhan Aktualisasi Diri)}

Aktualisasi diri merupakan kebutuhan yang berada paling atas atau puncak dari terpenuhinya empat kebutuhan di bawahnya. Terdapat empat belas bentuk yang menandai bahwa individu telah berhasil mencapai aktualisasi diri. Salah satunya adalah sifat jujur. Pada kutipan berikut, Dahlan membuktikan bahwa ia telah berhasil mengaktualisasikan dirinya yang dapat dilihat dari kejujurannya. 
"Belakangan ini sampean jarang kirim berita," tutur Yusril tanpa basa-basi, "pada saat yang sama, banyak kabar miring tentang berita yang sampean tulis dimuat di media lain di Jakarta." "Betul Mas," jawabku dengan jujur, "Saya kesal tidak banyak ruang yang tersedia buat kami di daerah, atau, kalaupun dimuat, paling digabung dengan berita-berita dari daerah lain.” Anehnya, Yusril tidak marah," (Pabichara: hlm. 302).

Dahlan, dengan kejujuranya, tanpa ragu mengatakan segala hal dengan apa adanya tanpa memperdulikan konsekuensi yang akan diterimanya. Bersyukur, juga, merupakan bentuk dari aktualisasi diri yang telah tercapai. Individu yang telah teraktualisasikan maka, ia akan lebih menghargai hidup dan selalu mengingat bahwa semua usahanya tidak akan berhasil tanpa adanya campur tangan Tuhan sebagai Maha pengabul segala doa umatnya. Hal ini terdapat pada kutipan berikut.

"Letih semalaman memikirkan pekerjaan langsung sirna begitu bercanda bersama Rully dan Isna. Sesuatu dibagian dadaku terasa penuh oleh rasa bahagia. Dan, apakah yang lebih menenangkan dan menyenangkan daripada perasaan bahagia. Pekerjaan yang menggiurkan, istri yang alangkah penyabar, dan anak-anak yang menggemaskan. Segalanya telah berubah. Aku telah menjalani hidup, sedari kecil hingga saat ini, dan menang melawan kecemasan atas suram nasib. Atas berkat Tuhan, aku telah mengatasi kepedihan, kesakitan, dan kemiskinan yang menghantuiku, dulu," (Pabichara: hlm. 308).

\section{SIMPULAN}

Hasil penelitian kajian psikologi humanistik pada tokoh utama dalam novel Surat Dahlan karya Khrisna Pabichara, dapat disimpulkan bahwa Kebutuhan fisiologis yang Dahlan butuhkan adalah pemenuhan kebutuhan tidur dan makan. Keduanya merupakan tindakan fisik, untuk mempertahankan kelangsungan hidup individu. Kebutuhan fisiologis yang tidak terpenuhi akan menimbulkan dampak yang buruk terhadap tubuh, mulai dari kehilangan banyak homeostasis sampai kematian.

Kebutuhan rasa aman Dahlan, terdapat pada kebutuhan perlindungan dan kebebasan. Kebutuhan ini dibutuhkan Dahlan ketika dirinya diliputi rasa cemas karena membayangkan nyawanya dihabisi tentara sewaktu aksi unjuk rasa yang dilakukannya gagal. Rasa cemas Dahlan membuktikan, ia membutuhkan the safety needs (kebutuhan rasa aman) dalam hal perlindungan, dan kebebasan.

Cinta dan kasih merupakan bagian dari kebutuhan the belongingness and love needs (kebutuhan cinta dan rasa memiliki-dimiliki) yang dapat dilihat dari keinginan individu dalam membangun sebuah hubungan, baik dengan lingkungan, keluarga, maupun lawan jenis. Dahlan membutuhkan cinta dan kasih dari seseorang yang ia harapkan yaitu Nafsiah.

Kebutuhan harga diri Dahlan, ia penuhi melalui kerja kerasnya dalam bekerja sebagai seorang wartawan. Kebutuhan harga diri yang pertama kali ia dapatkan adalah berupa pujian, pengakuan, dan kepercayaan, karena potensi yang dimiliki Dahlan. Puncak dari kesuksesan Dahlan adalah ketika ia dipercaya untuk memimpin Jawa pos.

Aktualisasi diri merupakan kebutuhan pada tingkat akhir yang dinilai sebagai tolak ukur atau pencapaian keberhasilan dalam memanfaatkan semaksimal mungkin potensi yang ada pada diri individu. Tokoh Dahlan yang digambarkan Pabichara, telah berhasil mencapai tingkat kebutuhan ini, yang dapat dilihat dari terpenuhinya empat tingkatan kebutuhan dibawahnya. Kriteria lainnya untuk mengukur bahwa individu tersebut sudah mengaktualisasikan dirinya, dapat melalui empat belas ciri-ciri individu yang teraktualisasi, Dahlan telah memiliki 
beberapa diantaranya yaitu sifat jujur, menyukai tantangan, tidak pernah takut gagal, lebih memahami hidup dengan banyak bersyukur, dan menerima setiap perbedaan yang ada

\section{DAFTAR PUSTAKA}

Afrizal. (2016). Metode Penelitian Kualitatif. Jakarta: Rajawali Pers. Jarvis, Matt. (2012). Teori-Teori Psikologi: Pendekatan Modern Untuk Memahami Perilaku, Perasaan, dan Pikiran Manusia. Bandung: Penerbit Nusa Media.

Maslow, Abraham H.. (1954). Motivation and Personality. New York: Harper \& Row, Publishers, Inc.

Minderop, Albertine. (2013). Psikologi Sastra: Karya Sastra, Metode, Teori, dan Contoh Kasus. Jakarta: Yayasan Pustaka Obor Indonesia.

Nurgiyantoro, Burhan. (2013). Teori Pengkajian Fiksi. Yogyakarta: Gajah Mada University Press.

Priyatni, Endah Tri. (2010). Membaca Sastra Dengan Ancangan Literasi Kritis. Jakarta: Bumi Aksara.

Sehandi, Yohanes. (2014). Mengenal 25 Teori Sastra. Yogyakarta: Penerbit Ombak.

Suaka, I Nyoman. (2014). Analisis Sastra: Teori dan Aplikasi. Yogyakarta: Penerbit Ombak.

Sugiyono. (2014). Memahami Penelitian Kualitatif. Bandung: ALFABETA, cv. .(2016). Metode Penelitian Pendidikan (Pendekatan Kuantitatif,

Kualitatif, dan R\&D). Bandung: ALFABETA, cv. 